question at present before us. In the result Mr. Gulick completely agreed with me, that it cannot signify how or when the physiological variation of initial cross-infertility arises; for to whatever causcs it may be due, and at whatever time in the process of varietal divergence it may first occur, it must alike furnish as highly important a condition to the origination of species as Mr. Wallace has eventually himself assigned to it.

I say "eventually," because Mr. Wallace has never before expressed himself to the effect that, in his opinion, cross-infertility is a factor of such prime importance in the origination of species. Why has he never done so? Surely the matter is one of sufficient magnitude to bave justified some mention in one or other of the many valuable "contributions" which he has made to the theory of evolution. Or, not to go further than his past criticisms of my own paper on the subject, what pages of controversy he miyht have saved in this journal and elsewhere by stating, at any time within the last four years, that he had no disagreement with me touching the probable occurrence, and the important consequence, of some degree of infertility characterizing varieties which afterwards, and on this account, develop into species; but merely doubted whether any degree of infertility could ever arise before differertiation of some other kind had begun to take place. Such criticism would have been mild indeed. But hitherto the crown and front of opposition to the theory of physiological selection has been that, in representing cross-infertility as a factor of any great importance in the origination of species, the theory is not only untrue in itself, but tends to "shrivel up nalural selection to very small dimensions." Now, however, criticism " changes front." It is no longer denied, but actually upheld, that "selective fertility" is as highly important a "co-operative cause in the origination of species" as I have ever claimed; and the new attack is directed only to a very subordinate point-a point, moreover, which both Mr. Gulick and myself had expressly anticipated, fully discussed, and shown not to belong to "the essence of the theory." 1

Oxford, December 22, 1890 . GEORge J. Romanes.

\section{Molecular Dispersion.}

In the notes that appeared in your journal of December II (p. 133), you gave a very full account of some papers lateiy published in the Bulletin de la Société Chimique de Paris, on optical dispersion, by Messrs. Barbier and Roux.

This investigation is a remarkable instance of how laborious and intelligent work may be almost wholly throw'n away for want of the knowledge of what has been previously done in the same direction. The authors commence their first paper with the astounding statement: "I)ispersion has never been studied from the point of view of the relations which connect this physical property of bodies with their composition, their molecular weight, and their chemical constitution." This, however, was atten pted by Sir John Herschel more than half a century ago, though with little success: and most of the scientific men who have hest elucidated the subject of molecular refraction, such as Mascart, Briihl, and Nasini, have paid some attention also to dispersion. Mr. Dale and I gave numerical values for dispersion equivalents, analogous to I andolt's "refraction equivalents," for $\mathrm{CH}_{2}, \mathrm{Cl}$, Sc., as far back as I866. The dispersion of isomeric bodies was treated by me in $188 \mathbf{1}$; and within the last few years I have communicated papers on the sur ject of milecular dispersion to learned Societies in England, France, and Switzerland. Some of the substances worked on by Messrs. Barbier ard Roux have not, I think, heen optically examined before; but the value of their careful observations is much diminished by their having measured two lines of the tin spectrum, instead of the $\mathrm{A}$ and $\mathrm{H}$ of the solar spectrum, or the $\alpha$

"P.S.-Mr. Wallace alludes to my "standards of scientific reasoning and literary consistency." As regards the former, I am satisfied with a full and independent corroboratic $\mathrm{n}$ by a consistent and a logical mind. As regards the latter, it is enough to quote the cuncluding words of my reply to Mr Wallace's first criticism of four years ago:"The main feature of the theory is what my paper states it to be-viz. that sterility with parent forms is one of the conditions, and not alworys one of the results, of specific differertiation. But. if so, is it not evident that all causes which induce steriluy are comprised by the theory, whether these causes hapren to affect a few individuals sporadically, a number of individuals simultaneously, or even the majority of an entire species",

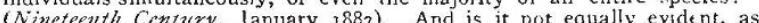
Ninetesith Centary, J anuary elseu here stated, that it does not signify whether the sterlity arises betore or after the "literen out the sterilty the diferentiation (as Mr wallace now says) will usually fail to proced to the which a Dar win's viewhis " which are expressed either here or in "Darwinism."

NO. I IO5, VOL. 43$]$ and $\gamma$ of that of hydrogen; thus their results cannot easily be compared with the hundreds of measurements of dispersion already published by others. They have unfortunately employed Cauchy's formula, and have taken as the "specific dispersive power," $\frac{\mathrm{B}}{d}$; that is, Cauchy's B divided by the density of the substance, instead of $\frac{n_{\alpha}-n_{b}}{d}$, the difference between the refraction of two lines divided by the density. Brihl commenced to work in the same way, but shows in a parer in Liebig's Annalen for August I886 that the method is unsatis. factory. The generalizations of our present authors are definite, and apparently correct, but they could have been mostly foreseer and explained if they had more clearly grasped the idea of molecular dispersion.

In the early summer I sent Messrs. Barbier and Roux copies of my papers on the subject; on August I they acknowledged receipt, and promised to refer in a forthcoming paper to previous work. As the paper reviewed in NATURE appeared in a preliminary abstract in the Comptes renaius of July, it is evident that they have yet something to bring before the public.

I7 Pembridge Square, December 27, 1890 .

\section{Weighing with a Ternary Series of Weights.}

In a former communication (NATURE, November 13, p. 30) I omitted, in order to avoid prolixity, to show how readily any given number may be expressed in the notation therein proposed. To effect this, it is only necessary to express the given number in the ternary scale, and then, beginning on the right, to substitute for 2 , wherever it occurs, - I, whilst increasing the previous figure by $\mathrm{I}$. When 3 occurs in the application of this rule, it must of course be replaced by $o$, the previous figure being again increased by $r$.

Examples :- -

$4 \mathrm{I}$ is in ternary notation $\mathrm{III} 2$, in new notation 11111 . 500 ," ," $2001 \mathrm{I} 2$, , , $110 \mathrm{llll}$ 71 ", ", ", $2122, \quad, \quad, \quad$ IOlO1.

Or (still more briefly) in dividing by 3 , to express the number in the ternary scale, we may substitute for the remainder 2 , wherever it occurs, $-\mathbf{I}$, and increase the quotient by $\mathbf{I}$.

Examples :-

\begin{tabular}{|c|c|c|c|c|c|c|c|c|}
\hline \multicolumn{3}{|l|}{425} & \multicolumn{3}{|l|}{474} & \\
\hline $4^{2}$ & nain & -1 & \multicolumn{3}{|c|}{$\begin{array}{l}474 \\
158 \text { remainder }\end{array}$} & \multicolumn{3}{|c|}{$\begin{array}{l}500 \\
\mathrm{I} 67 \text { remainder - I }\end{array}$} \\
\hline 47 &, & I & 53 & ," & $-\mathbf{I}$ & $5^{6}$ & $n$ & $-I$ \\
\hline 16 & ," & $-I$ & 18 & ," & $-\mathbf{I}$ & I9 & ", & $-I$ \\
\hline 5 & $"$ & I & 6 & ," & o & 6 & ," & I \\
\hline 2 & ", & $-\mathbf{I}$ & 2 & ", & 0 & 2 & ," & 0 \\
\hline I & , & $\cdots \mathbf{I}$ & I &, & $-\mathbf{I}$ & I & ,", & $-I$ \\
\hline 0 & ," & I & 0 & ," & I & 0 & ," & I \\
\hline & \multicolumn{3}{|c|}{-............. } \\
\hline \multicolumn{3}{|c|}{$\begin{array}{c}3+27+729 \\
-(\mathbf{I}+9+81+243)\end{array}$} & \multicolumn{3}{|c|}{$729-(3+9+243)$} & \multicolumn{3}{|c|}{$\begin{array}{c}27+729 \\
-(\mathrm{r}+3+9+243)\end{array}$} \\
\hline
\end{tabular}

Bradford, December I3, 1890 .

J. WILLIS.

Prof. EveretT's rule (Nature, December 4, p. IO4) is needlessly complicated. All that is necessary is to express the given weight in the ternary scale with digits that are either $O_{\text {, }}$ $+\mathbf{I}$, or - I. His example is thus solved :-

$$
\begin{aligned}
& \text { 3) } 500 \\
& \text { 3) } 167 \text { - I } \\
& \text { 3) } 56-1 \\
& \text { 3) } 19 \text { - I } \\
& \text { 3) } 6+1 \\
& \text { 3) } 2+0 \\
& \text { I - I }
\end{aligned}
$$$$
\text { or } 500=\text { İ̃oI İī ternary }
$$$$
=729-243+27-9-3-\mathbf{I} \text {. }
$$

We thus see generally that, to express weights in units and powers of $n$, we must be provided with $\frac{1}{2} n$ or $\frac{1}{2}(n-1)$ balance- 